\title{
Electronic Aids to Education and Practice in Radiology: The Personal Computer in the Radiologist's Office
}

Tim B. Hunter

C OMPUTERS are not only tools for clinical imaging and research, they are also an everyday tool for routine departmental applications such as patient-examination scheduling, flow statistics, billing, inventory, patient diagnostic reports, and economic planning. ${ }^{1-16}$ For a modest investment in hardware and software the radiologist can equip an office with a powerful microcomputer system that will greatly enhance the ability to do work..$^{1-3,9,11-16}$

\section{HARDWARE AND SOFTWARE FOR THE OFFICE}

What is the ideal personal computer (PC) system? There are as many opinions as there are computers. The answer depends on the user's goals and reasons for purchasing a computer system. A typical, reasonably powerful system can be purchased for $\$ 3,000$ to $\$ 5,000$. My own recommendations for a minimum professional computer system: a comfortable keyboard; a high-quality monochrome CRT monitor, at least 512 Kbytes of random access memory; and at least two floppy-disk drives. If possible, a 10- to 30-Mbyte hard-disk drive should be substituted for one of the floppy-disk drives. A printer is mandatory. Very fine matrix printers can be purchased for less than $\$ 500$. Ideally, a printer should be able to handle both fan-fold paper, single-sheet paper, and envelopes. Some inexpensive printers can handle both fan-fold paper and single-sheet paper at the same time.

Any system should be readily expandable. It is highly desirable that there be several free slots available in the main computer system so that internal boards for a phone modem, extra memory, an internal clock, etc, can be added as time and money permit. It is most important to visit a computer store and work with several computer keyboards and monitors before selecting one system.

\section{APPLICATIONS}

Computers may save time and money but they are not cheap; they have minor upkeep costs and they should not be used for small, trivial tasks that can be better done by other methods. If you only go into your office to hang up your coat, pay a few bills, or to read an occasional article, then a powerful computer system would be a waste of time for you. However, if you manage the business aspects of your radiology group or department, have extensive correspondence, write professional papers, and perform research, a good computer system is mandatory. Even the most inexperienced computer user can quickly find applications for one (Table 1). These include learning how to type, dialing into national databases, finding out about continuing medical education (CME) courses, and making airline reservations. $^{3}$

\section{Word Processing}

Word processing is by far the most widely used software for the average PC user. Many types of word processors are available for purchase. They range from the very complex and expensive to the very simple and inexpensive. The more complex programs are more difficult to learn but have much more power and allow many more options. Features to look for in a good word processor are: availability of help files, ease in moving around blocks of text, capability of responding to errors, ease of transferring text files to another system, and especially the accuracy of the final printed document compared with the text on the screen. ${ }^{3}$ It is most helpful to have a software program that gives you WYSIWYG (what you see is what you get). Spelling and grammar checkers and synonym lists are often included with word processors and are very helpful.

\section{Spreadhseets and Database Management}

These programs are useful for creating budgets, building business models, and forecasting

From the Department of Radiology, Arizona Health Sciences Center, University of Arizona, Tucson.

Address reprint requests to Tim B. Hunter, MD, Department of Radiology, Arizona Health Sciences Center, University of Arizona, Tucson, AZ 85724.

() 1989 by W.B. Saunders Company.

0897-1889/89/0202-00004\$03.00/0 
Table 1. Some Uses for the Personal Computer

Word processing: papers, letters, reports
Spreadsheet: financial tabulations, calculations, projections
Database management: reference lists, slide catalog, research
projects, patient demographics
Statistics
Mailing lists, inventory, payroll
Appointment calendars
Work schedules
Networking/communications: intra-/interoffice, national,
international
Education: typing, programming, CME, statistics; computer-
generated examinations
Computer-Aided Equipment Design (CAD)
Graphs, charts, slide production
Games: professional relaxation
Software development

trends. Spreadsheet programs are a computerized version of an accountant's ledger. Many of them have relatively powerful built-in graphics so that results can be displayed as line graphs, bar graphs, and pie charts. The larger spreadsheet programs keep track of hundreds of rows of columns and figures. Database management is an extraordinarily powerful application for the radiologist's office. These programs range from simple file-card-type software to complex, very expensive software that manipulates hundreds of thousands of files in hundreds of fields. The larger, more expensive and more sophisticated programs have their own procedural language and are difficult to learn. Nevertheless, once they are learned, the amount and types of data they can process and sort is remarkable, and they are well worth the cost and effort of installation.

Uses for a database system are legion. " A busy outpatient imaging clinic might store names, addresses, patient numbers, diagnoses, and billing particulars for its patients. Individual radiologists might use database management to keep citations from medical literature. - $^{5-9,13-15}$ A slide collection could also be easily kept on a database managment system.

Some key points to consider about spreadsheet programs and database programs, besides the program's price and ease of use, are their ability to move data around and to change data formats. ${ }^{3}$ Ideally, these programs should accept data in nonstandard formats and convert data to useable formats. They should accept files from other database or spreadsheet programs, should have a great deal of tolerance for different data field sizes, and should support a large number of fields.

There are also integration packages that combine individual programs, such as a word processor, a spreadsheet program, and a database program, into an integrated software package. In this fashion the user can compose a letter, survey a database, and access his spreadsheet with one program, without having to constantly change to another program or file. These programs, such as the Symphony Package from Lotus Software Incorporated (Cambridge, MA) and Framework from Ashton Tate Corporation (Torrance, CA), usually are complex and require a great deal of time to learn properly. Once learned, they offer the user a great deal of flexibility for little time and effort.

\section{Telecommunications}

There are many commerical and nonprofit computer networks that allow access to large national and international databases ${ }^{3,8}$ To dial into another computer it is necessary to have a modem and proper communication software. Most dial-up computer systems do require an appropriate password and charge an hourly fee of $\$ 5$ to $\$ 100$ per hour. The three most popular general purpose computer networks are BIX, The Source, and CompuServe. They provide electronic mail, electronic bulletin boards, medical special interest groups, financial information, electronic shopping, news items, and airline ticket reservations.

Extensive medical database services can be purchased from many sources. These permit nearly instantaneous access to current article citations and abstracts and millions of articles in the medical literature. Most medical reference systems are based on the National Library of Medicine's database and retrieval services. National networks may charge up to $\$ 100$ per hour for medical searches and it is possible to incur large bills rather quickly. If you carefully study the network's manuals, learn how to use its help files, take a training course in how to search its medical databases, and think through your research strategies carefully, it is possible to obtain the desired reference information for very little 
cost, particularly compared with the alternative of spending hours in a medical library wandering through the stacks.

\section{Computer Networking}

Microcomputers are often installed in many locations in a radiology department including the reception desk, the transcription office, qualitycontrol stations, workrooms, and radiologists' offices. Hardware and software are readily available to network these computers. ${ }^{10}$ Once they are interconnected to common communication links, there can be sharing of common databases and expensive peripheral devices like large disk drives and laser printers. Now the radiologist can monitor departmental functions from the office using a microcomputer linked to the other departmental computers.

\section{BACKUP. OF IMPORTANT COMPUTER INFORMATION}

Nothing is more important for the computer user than proper backup of valuable programs and data. It is inevitable that a disk "crashes," or gets inadvertantly erased. Literally, a year's work can be suddenly lost. Computers can lose more information in a second than would be possible by throwing a couple of sticks of dynamite into your office. It is absolutely mandatory to have backups for any and all valuable files. You have to develop your own backup methods and they should be followed conscientiously at all times. Backing up small amounts of data on floppy disks is easy enough. For a large amount of data, it may be necessary to purchase some type of cassette-tape backup system. Whatever method is chosen, it is good practice to have a set routine and to follow it religiously.

\section{HOW TO GET STARTED IN COMPUTERS AND HOW TO KEEP UP}

The best way for a beginner to get started is to find a good computer buddy and to take a short course through a local computer store or community college. The course instructor or your computer buddy will introduce you to more uses than you would have thought possible and will help you solve your seemingly complex problems. Magazines provide the best ongoing method for keeping up (Table 2). They review hardware and software and publish articles of general interest. $B Y T E$ is the most popular magazine for the microcomputer world. It offers a wealth of articles, reviews, ads, and bylines, and is highly recommended. It can be somewhat difficult reading at first but the articles vary greatly in their complexity and there are many simple articles in any given issue. Many people find reading the advertisements in BYTE the single best method for keeping track of the ever-changing computer industry. $M$. D. Computing is an excellent, practical journal for the average physician computer user and is highly recommended. $A J R$ has a special section, "The Computer Page," for computers in radiology, and Radiology regularly features computer articles.

\section{COPYRIGHT CONSIDERATIONS}

Commercial software is usually the proprietary of the vendor and it is almost always copyrighted. Therefore, it cannot be legally copied or resold without prior permission of the

Table 2. Useful Books and Journals

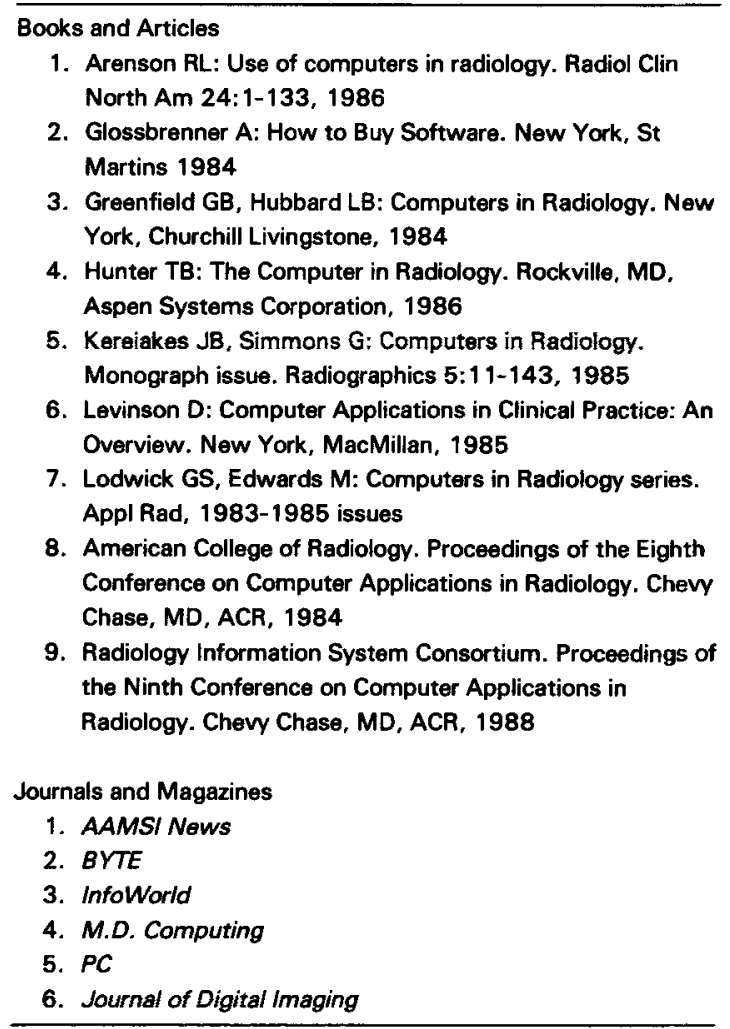


copyright holder. It is illegal to "pirate" a copy for a friend or to copy a friend's software. Today the software industry is very competitive, and most successful programs are well designed and relatively inexpensive. For ethical and practical reasons, it is recommended you purchase and use commercial software in an above-board, legal fashion.

\section{REFERENCES}

1. Newell JD, Hunter TB: Personal computer needs for the radiologists. Invest Radiol 21:167-169, 1986

2. Newell JD, Hunter TB: Introduction to the personal computer for the practicing radiologist. Contemp Diagn Radiol 9:1-6, 1986

3. Seeley GW: The personal computer: Uses, in Hunter TB (ed): The Computer in Radiology. Rockville, MD, Aspen 'Systems Corporation, 1986

4. Hunter TB: Keeping up with computers and their applications in medicine. AJR 143:678-680, 1984

5. Kunin CM: Managing bibliographic citations using microcomputers. Am J Med 78:625-634, 1985

6. Relman AS: Ripping and filing Journal articles. N Engl J Med 311:925, 1984

7. Hunter TB: Ripping and filing Journal articles. N Engl J Med 311:1639, 1984

8. Rowberg AH, Newell JD, Hunter TB: Computer Page. Telecomputing in Radiology. AJR 145:411-413, 1985
9. Gurney JW, Wigton RS: Computerized reference management: Searching the literature. AJR 147:641-645, 1986

10. Markivee CR: Networking of microcomputers in the radiology department. AJR 145:849-853, 1986

11. Somer FG: Some applications for a personal computer database system in radiology. AJR 147:1075-1077, 1986

12. Chew FS, Hefner ML: Computer-aided design and realization of scientific exhibits in radiology. AJR 149: 195-198, 1987

13. Sistrom CL, Black WC: Computerized filing system for radiology teaching cases. AJR 149:191-194, 1987

14. Gurney JW, Wigton RS: Computer reference management-Filing the literature. AJR 149:41 1-413, 1987

15. Amis ES Jr: Microcomputer applications for the academic radiologist. AJR 149:187-190, 1987

16. Taylor GA: Microcomputer-based graphics for radiology. AJR 147:1319-1321, 1986 